\title{
Saint Kitts and Nevis
}

National Cancer Institute

\section{Source}

National Cancer Institute. Saint Kitts and Nevis. NCI Thesaurus. Code C17885.

A group of islands in the Caribbean Sea, east of the Virg in Islands and south of Anguilla. 